DOI 10.36796/biolex.v22i0.171

\title{
ESQUEMAS TRIBUTARIOS DE LAS ENTIDADES NO LUCRATIVAS EN MÉXICO
}

\section{Daniel Eduardo Paz Pérez}

\begin{abstract}
SUMARIO: I.Introducción.II. Antecedentes de las ENL en la Ley del ISR.III.Metodología.IV.Resultados.V.Conclusiones
\end{abstract}

\begin{abstract}
RESUMEN
Las entidades no lucrativas juegan un papel importante desde la iniciativa social, ya que realizan un amplio rango de actividades: desde lo asistencial hasta lo filantrópico, sin ánimo de especulación comercial. El objetivo de esta investigación fue mostrar cómo tributan estas entidades, así como su evolución en el sistema tributario mexicano, utilizando el análisis documental histórico y el método interpretativo exegético a partir de la legislación mexicana en el siglo XX. El principal hallazgo es el reconocimiento de las organizaciones a las que se les ha ido concediendo la exención tributaria en las leyes mexicanas de renta, así como los esquemas tributarios que le son aplicables a las entidades no lucrativas en la legislación vigente.
\end{abstract}

Palabras clave: Beneficios fiscales, entidades no lucrativas, ENL, esquema tributario.

\section{TAX SCHEMES OF NON PROFIT ENTITIES IN MEXICO}

\section{Daniel Eduardo Paz Pérez}

SUMMARY: I. Introduction. II. Background of the ENL in the Income Tax Law III.Methodology IV.Results V. Conclusions

${ }^{1}$ Contador Público, Maestro en Fiscal y Doctor en Materia Fiscal, profesor investigador del Tecnológico Nacional de México/ITS de El Mante, en la Academia de Ingeniería en Gestión Empresarial, dentro de las líneas de investigación empresarial y educativa. Código Orcid: https://orcid.org/0000-0003-0511$\underline{2776}$ depaz@itsmante.edu.mx 


\title{
Esquemas tributarios de las entidades No lucrativas en México
}

\section{Volumen 12, Número 22 ene-jun 2020}

Daniel Eduardo Paz Pérez

\begin{abstract}
Non-profit entities play an important role from the social initiative, since they conduct a wide range of activities: from healthcare to philanthropy, without bussines speculation intention. The objective of this research was to show how these entities are taxed, as well as their evolution in mexican tax system, using the historical documentary analysis and exegetical interpretative method in mexican 20th century legislation. The main finding is the recognition of the organizations granted with tax exemption in mexican income laws, as well as tax schemes that are applicable to non-profit entities in current law.
\end{abstract}

Key words:Tax benefits, Non-profit organizations, NPO, tax scheme.

\section{INTRODUCCIÓN}

Las Entidades No Lucrativas (ENL) son personas jurídicas colectivas reconocidas por diversas leyes en México, integradas por individuos u otras personas legales a quienes se les considera como una sola entidad con capacidad jurídica plena; se les reconoce por ser organizaciones que realizan un amplio rango de actividades que van desde lo asistencial hasta lo filantrópico, todo ello sin ánimo de especulación comercial y desde la iniciativa social2 3 ; suelen ser instituciones reconocidas por su altruismo y aportan un gran beneficio a la sociedad. La Norma de Información Financiera NIF-A2 señala que las entidades no lucrativas son aquellas que persiguen solamente los fines para los cuales fueron creadas, que están enfocadas en el beneficio social y sin la pretensión de retribuir económicamente a sus integrantes o patrocinadores 4 .

En el presente estudio se realiza una investigación sobre la regulación tributaria de las ENL en la legislación mexicana; es un tema trascendente, ya que en el país existen entre 30,000 y 60,000 instituciones sin ánimo de lucro, en las cuales trabajan más de 2’440,000 voluntarios y generan el 3\%

\footnotetext{
2 Centro Interamericano de Administraciones Tributaria. Los sistemas tributarios de América Latina. Breve repaso de la legislación. Serie Comparativa No. 1, 2016, pp. 288-316.

3 Gobierno del Estado de México. Glosario de términos. Toluca, Gobierno del Estado de México, 2013.

4 Pérez-Cervantes et al. Normas de Información Financiera. Ciudad de México, Instituto Mexicano de Contadores Públicos, 2017.
} 
del PIB nacional, las cuales suelen ser estudiadas desde los ámbitos social, financiero 0 administrativo, pero rara vez desde un enfoque tributario 5678 .

Para su estudio, existe una clasificación de estas entidades elaborada por el Centro John Hopkins, que es utilizada internacionalmente y nos permite ubicarles en sus distintas actividades, según se aprecia en la tabla 1 siguiente:

Tabla 1.- Clasificación Internacional de Organizaciones Sin Fines de Lucro (CIOSFL).

\begin{tabular}{|l|c|}
\hline Grupo 1: Cultura y Recreación & Grupo 7: Justicia; Defensa y Política \\
\hline Grupo 2: Educación e Investigación & Grupo 8: Intermediarios Filantrópicos y \\
& Promoción del Voluntariado \\
\hline Grupo 3: Salud & Grupo 9: Internacional \\
\hline Grupo 4: Servicios Sociales & Grupo 10: Religión \\
\hline Grupo 5: Medio Ambiente & Grupo 11: Sindicatos, Asociaciones \\
\hline Grupo 6: Desarrollo y Servicios de Alojamiento & Grupo 12: No clasificados previamente \\
\hline
\end{tabular}

Fuente: INEGI (2019).

Históricamente, a las ENL se les consideró exentas de impuestos en la legislación tributaria mexicana, pues se reconoce en su labor altruista la realización de actividades propias del Estado9; por su importancia en este trabajo, conviene definir la exención fiscal: Ponce \& Ponce ${ }^{10}$ nos dicen que "es una figura jurídica tributaria, en virtud de la cual se eliminan de la regla general de causación ciertos hechos o situaciones imposibles, por razones de seguridad, conveniencia o política económica"; luego entonces, la exención se concede en forma general e impersonal cuando se libera a un grupo de personas de cumplir el pago de la carga fiscal, mientras que a los demás no.

Como ejemplo de la exención general, en mayo de 1896 se concedió a las Juntas de Beneficencia del país exención de derechos de importación para introducir toneladas de maíz que venderían a precio

\footnotetext{
5 Butcher, J., \& Verduzco, G. Acción voluntaria y voluntariado en México. Ciudad de México, Ed. Fundación Telefónica México, S.A. de C.V; Ediciones Culturales Paidós, S.A. de C.V., 2016.

${ }^{6}$ Chávez-Chávez, J. L. La planeación fiscal a través de las asociaciones civiles. INCEPTUM, Vol. XIII, No. 24, 2018, pp. 322.

7 INEGI. Cuenta Satélite de las Instituciones sin Fines de Lucro de México, 2018. Ciudad de México, Instituto Nacional de Estadística y Geografía, 2018.

8 José Manuel Suárez-Noriega. En busca de la libertad auto-organizada: emprendimiento juvenil. En Centro Mexicano de Filantropía, Memorias del XV Congreso de Investigación sobre el Tercer Sector. México DF, Ed. Cemefi, pp. 806-827.

${ }^{9}$ González Castillo, V. Mejores prácticas administrativas para organizaciones no lucrativas. Contaduría Pública Núm. 428, 2008, pp. 8-10.

10 Francisco Ponce y Rodolfo Ponce. Derecho Fiscal Décima segunda edición. México: Editorial Limusa Noriega, 2012.
} 


\section{Esquemas tributarios de las entidades No lucrativas en México}

\section{Volumen 12, Número 22 ene-jun 2020}

Daniel Eduardo Paz Pérez

de costo en pueblos de Veracruz, San Luis Potosí y Tamaulipas, con motivo de la escasez de granos que se vivía en aquella época ${ }^{11} 12$.

En forma excepcional, sin embargo, se les consideró sujetos de impuesto; como ejemplo, en ocasión del Impuesto especial del Timbre sobre los capitales que administren las Instituciones de Beneficencia Privada, emitido mediante decreto del Ejecutivo el 19 de julio de 1917, se gravó el capital afecto a este tipo de entidades en particular, las de beneficiencia ${ }^{13}$. En la actualidad muchas organizaciones se han sumado a la lista de entidades no lucrativas; partiendo de lo anterior, las preguntas que guían esta investigación son: ¿qué tratamiento fiscal tuvieron históricamente las ENL en las leyes de renta mexicanas? y ¿cómo es su tratamiento tributario en la ley vigente en 2019 ?.

\section{ANTECEDENTES DE LAS ENL EN LA LEY DEL ISR}

A partir de la revisión y análisis de las leyes de renta que han estado vigentes durante el siglo XX y XXI en México, se presenta en orden cronológico un resumen sobre las disposiciones relacionadas con las organizaciones sujeto de estudio.

\section{Ley del Centenario}

Esta ley fue promulgada el 28 de julio de 1921, a la que se le conoció como Ley del Centenario porque coincidía con los 100 años de la independencia mexicana; establecía un impuesto federal, extraordinario y pagadero una sola vez sobre las ganancias o los ingresos obtenidos en las siguientes categorías: 1) la industria y el comercio, 2) las profesiones independientes, 3) el trabajo de los asalariados y 4) la obtención de rentas o dividendos; se le considera precursora de las posteriores leyes de renta, porque no fue permanente y además no permitía disminuir gastos e inversiones, tampoco contempló una clasificación de contribuyentes ni hizo distinción entre negocios lucrativos y no lucrativos ${ }^{14}$.

\footnotetext{
11 Leandro Fernández. Memoria de la Secretaría de Hacienda y Crédito Público correspondiente al septuagésimo primer año económico. Ciudad de México, Tipografía de la Oficina Impresora de Estampillas, Palacio Nacional, 1896.

12 Antonio Escobar Ohmstede. Desastres agrícolas en México. Catálogo histórico II. Siglo XIX (1822-1900). México, Ed. Fondo de Cultura Económica CIESAS, 2004.

13 Secretaría de Gobernación. Recopilación de Leyes y Decretos expedidos por los poderes Legislativo y Ejecutivo de la Unión de mayo a diciembre de 1917. México DF, Imprenta de la Secretaría de Gobernación, 1917.

${ }^{14}$ Enrique Calvo Nicolau. Tratado del Impuesto sobre la Renta. México DF, Editorial Themis S.A., 2013.
} 
Ley de 1924

La primera ley formal de renta fue promulgada el 25 de febrero de 1924 bajo el nombre de Ley para la recaudación de los impuestos establecidos en la Ley de Ingresos vigente sobre sueldos, salarios, emolumentos, honorarios y utilidades de las sociedades y empresas; estableció cédulas para cada categoría y permitió las deducciones sobre los ingresos; en su capítulo II denominado "Impuesto sobre las utilidades de las sociedades y empresas" impuso el gravamen para toda clase de sociedades anónimas, comanditarias, colectivas, cooperativas, civiles, en participación y negocios particulares, con excepción de las negociaciones agrícolas; también concedió en su artículo 12 exenciones al gravamen a las instituciones de beneficencia, a las asociaciones cientificas, literarias, artísticas, políticas, religiosas, deportivas, a las organizaciones no lucrativas en general y a las sociedades cooperativas de consumo y producción; el requisito esencial era obtener una declaración de exención a solicitud de la parte interesada ${ }^{15}$.

\section{Ley de 1925}

Fue la primera con el nombre Ley del Impuesto Sobre la Renta, promulgada el 18 de marzo de 1925, aunque aún no incorporaba una sección propia para las entidades no lucrativas; ya establecía en su artículo primero como sujetos del impuesto a las sociedades civiles o mercantiles, las fundaciones, asociaciones, mancomunidades y otras agrupaciones que obtuvieran ingresos de fuente nacional; además, contemplaba en el artículo tercero la exención del impuesto para aquellas organizaciones ubicadas en sus seis fracciones. Esta ley ampliaba las exenciones establecidas en la Ley de 1924, pero a partir de adiciones a la Ley publicadas en diciembre de 1931 se eliminaban las exenciones cuando los contribuyentes mencionados antes rebasaran el tope de ingresos establecido por ley ${ }^{16}$.

Ley de 1942

En la Ley del ISR publicada el 31 de diciembre de 1941 aparecen como sujetos del impuesto las mismas entidades de la ley anterior, y entre los sujetos exentos del pago del impuesto del artículo tercero se agrega una fracción séptima para los que obtengan ingresos por la explotación de películas

15 Luis Aboites. Excepciones y privilegios. Modernización tributaria y centralización en México, 1922-1972. México DF, El Colegio de México, Centro de Estudios Históricos, 2003.

16 Luis Aboites. Excepciones y privilegios. Modernización tributaria y centralización en México, 1922-1972. México DF, El Colegio de México, Centro de Estudios Históricos, 2003. 


\section{Esquemas tributarios de las entidades No lucrativas en México}

\section{Volumen 12, Número 22 ene-jun 2020}

Daniel Eduardo Paz Pérez

nacionales; es la única ocasión en la que estuvo exenta, y en la actualidad esta industria aporta impuestos por más de 4,000 millones de pesos anuales ${ }^{17}$. También se agregó un artículo 11 para establecer que las personas que ocasionalmente ejecutaran actos de comercio -sin ser comerciantesdeberían pagar una tasa del $4 \%$ sobre dichas ganancias.

Ley de 1954

La Ley del ISR publicada el 31 de diciembre de 1953 permanece sin muchos cambios: se señalan como sujetos del impuesto, además de los mencionados en las leyes anteriores, a las agrupaciones aún sin organización jurídica; también se agregaron tres categorías más de sujetos exentos, entre ellos las sociedades locales de crédito agropecuario y rural, a fin de ayudar al desarrollo de las empresas agrícolas y se incorporaron las sociedades mutualistas de seguros ${ }^{18} 19$.

\section{Ley de 1965}

En la Ley del ISR publicada el 31 de diciembre de 1964 se eliminaron como sujetos del impuesto los nombres de las sociedades que mencionaba el artículo 6 de la Ley abrogada, para sustituirse por el término genérico personas morales, además de incluir también a las unidades económicas sin personalidad jurídica; en contraparte, se amplió a catorce el número de categorías exentas, entre ellas las sociedades cooperativas de productores, que estarán por segunda ocasión en la ley, ya que en las leyes anteriores se les obligó a tributar como los demás contribuyentes.

Ley de 1981

En la Ley del ISR publicada el 30 de diciembre de 1980 se incorpora el Título III "De las Personas Morales con Fines no Lucrativos" cuyo artículo 68 menciona: "Las sociedades y asociaciones civiles, las sociedades cooperativas y en general las personas morales distintas de las comprendidas en el Título

\footnotetext{
17 Instituto Mexicano de Cinematografía. Anuario estadístico de cine mexicano 2018. Ciudad de México, Instituto Mexicano de Cinematografía, 2019.

18 J. Reyes Altamirano Cárdenas. La Reforma al Sistema de Aseguramiento Agropecuario y la Participación de los Productores Organizados en la Operación del Seguro. Ciudad de México, Comisión Nacional de Seguros y Fianzas, 2001.

19 Sergio Reyes Osorio y Emiliano Reyes Rives. La historia del crédito agrícola en México. Ciudad de México, Centro de Estudios para el Desarrollo Rural Sustentable y la Soberanía Alimentaria (CEDRSSA), 2018.
} 
Il de esta Ley, no son contribuyentes del impuesto sobre la renta". Además de las organizaciones señaladas en dicho precepto, se configuró en el artículo 70 un listado de las entidades que no son contribuyentes del mencionado impuesto, agrupando a aquellos que antes se enunciaban en otros artículos y eliminando a los ejidatarios, cooperativas de productores y propietarios de automóviles de alquiler.

Ley de 2002

En la nueva Ley del ISR publicada el 1 de enero de 2002 se modifica el numeral para corresponder al artículo 95 el listado de las personas morales con fines no lucrativos; en su fracción XVI se inscribe puntualmente a las asociaciones religiosas como no contribuyentes del impuesto, dado su nacimiento como figuras jurídicas con la promulgación en 1992 de la Ley de Asociaciones Religiosas y Culto Público, junto con las sociedades de inversión especializadas de fondos para el retiro ${ }^{20} 21$; la lista crece a veinte fracciones para considerar nuevos sujetos exentos, incluyendo las instituciones educativas a las que se les exige la autorización o reconocimiento de validez oficial de estudios ${ }^{22}$. En la reforma a esta Ley en 2006 se adiciona un Capítulo VII-A "De las Sociedades Cooperativas de Producción" que les permite pagar el ISR en el Título de personas físicas cuando otorguen utilidades a sus integrantes, en lugar de hacerlo conforme las disposiciones para personas morales ${ }^{23}$.

Ley de 2014

Por último, la Ley del Impuesto Sobre la Renta vigente en nuestro país publicada el 11 de diciembre de 2013, considera sujetos de este régimen a por lo menos 25 tipos de entidades no lucrativas, cinco sujetos más que en la Ley anterior, a los cuales no se les reconocía directamente como no contribuyentes sino que se les liberaba de algunas obligaciones formales; era el caso de la Federación, los Estados y municipios, cuya única obligación era retener y enterar el impuesto cuando realizaran operaciones con terceros, pero que ya desde el Código Civil Federal de 1929 en la fracción I de su

\footnotetext{
${ }^{20}$ Garduño Martínez, A. Asociaciones Religiosas: ¿Entidades No Contribuyentes del Impuesto Sobre la Renta? Boletín Fiscal IEE, 2015, pp. 33-37.

21 Jorge Lee Galindo. Ley de Asociaciones Religiosas y Culto Público Comentada. Ciudad de México, Editorial SISTA S.A. de C.V., 2009.

22 Javier Belmares Sánchez. Bitácora Fiscal Enciclopédica 2005 3a Edición. Ciudad de México, Sistemas de Información Contable y Administrativa Computarizada, S.A. de C.V., 2005.

${ }^{23}$ Izquierdo, M. E. Cooperativas de producción en México y reformas fiscales. Boletín de la Asociación Internacional de Derecho Cooperativo, 2016, pp. 103-126.
} 


\section{Esquemas tributarios de las entidades No lucrativas en México}

\section{Volumen 12, Número 22 ene-jun 2020}

Daniel Eduardo Paz Pérez

artículo 25 les consideraba personas morales ${ }^{24}$. En esta Ley se elimina el Capítulo VII-A de la Ley anterior y se adiciona un Capítulo VII "De las Sociedades Cooperativas de Producción" para permitirles pagar el ISR en el Título de Personas Físicas, pero en la sección II de Actividades Empresariales ${ }^{25}$.

Es importante señalar que en el diciembre de 1990 nace para algunos contribuyentes la obligación de dictaminar los estados financieros para efectos fiscales, estando las ENL sujetas a ello si tuvieren en el año anterior ingresos o activos superiores a los establecidos en el artículo 32-A Código Fiscal de la Federación (CFF), o más de 300 trabajadores a su servicio en el mismo periodo; en octubre de 1991 nace el dictamen simplificado para las Donatarias Autorizadas; en diciembre de 1998 se eliminan de la exención del dictamen a las instituciones de asistencia o beneficencia autorizadas por ley; en 2001 se exceptuaron del dictamen fiscal a los organismos gubernamentales y fideicomisos con fines no lucrativos, excepto cuando realicen actividades emrpesariales ${ }^{26}$.

La Tabla 2 siguiente ofrece una síntesis de la revisión de las 8 leyes del Impuesto Sobre la Renta comentadas, tal y como fueron publicadas en el Diario Oficial de la Federación, con las personas morales exentas y la fracción en la que se ubicaron, además de un ejercicio propio de identificación de las ENL de la Ley de ISR con las 12 categorías CIOSFL señaladas antes; en dicha Tabla se puede apreciar que en las leyes de 1925 y 1941 se contemplaron solamente seis categorías de sujetos exentos, que tuvieron vigencia durante 28 años; posteriormente, en la ley de 1953 se agregaron tres categorías más; es hasta la Ley de 1964 que crece el número de sujetos exentos a 14 categorías, en cuatro fracciones del art. 5. La ley de 1980 define un nuevo apartado para estas entidades y reorganiza los sujetos en 12 categorías, que crecerán a 20 en la Ley de 2002 y a 25 en la Ley de 2013.

También se observa la inclusión temporal de las cooperativas de productores, los editores de libros culturales, los propietarios de vehículos de alquiler y los dedicados a la explotación de películas nacionales como sujetos exentos, y la remoción de la minería y los ejidatarios, estos últimos se

\footnotetext{
24 Jorge Fernández-Ruiz. Régimen Jurídico Municipal, Delegacional y Metropolitano. Ciudad de México, Instituto Nacional de Administración Pública, A.C., 2017.

25 Izquierdo, M. E. Cooperativas de producción en México y reformas fiscales. Boletín de la Asociación Internacional de Derecho Cooperativo, 2016, pp. 103-126.

${ }^{26}$ Fernando López Cruz. Dictamen Fiscal. México DF, Instituto Mexicano de Contadores Públicos, A.C., 2012.
} 
incluyeron en una nueva sección dedicada a las actividades agrícolas en la Ley, en la que se reguló la exención creando el régimen simplificado a partir de $1990^{27}$.

Tabla 2. Comparativo histórico de las ENL en las Leyes de Renta en México.

\begin{tabular}{|c|c|c|c|c|c|c|c|c|c|}
\hline Persona moral exenta o no contribuyente & CIOSFL & 1924 & 1925 & 1941 & 1953 & 1964 & 1980 & 2002 & 2013 \\
\hline Artículo de la Ley y fracción & & 12 & 3 & 3 & 18 & 5 & 70 & 95 & 79 \\
\hline Sindicatos obreros y organismos que los agrupen & 11 & & IV & IV & V & III & 1 & I & I \\
\hline Asociaciones patronales & 11 & & IV & IV & V & III & $\|$ & $\|$ & $\|$ \\
\hline $\begin{array}{l}\text { Cámaras de comercio e industria, minería *4, agrupacio- } \\
\text { nes agrícolas, ganaderas, pesqueras o silvícolas * } 4\end{array}$ & 11 & II-V & III & III & IV & ॥ & III & III & III \\
\hline Colegios de profesionales & 11 & & IV & IV & V & III & IV & IV & IV \\
\hline Distritos de riego (AC y SRL de IP) & 12 & & & & & & & V & V \\
\hline $\begin{array}{l}\text { Instituciones de asistencia o de beneficencia, sociedades o } \\
\text { asociaciones que reciben donativos }\end{array}$ & 8 & III & I & I & ॥ & IV e & VI & $\mathrm{VI}$ & $\mathrm{VI}$ \\
\hline Sociedades locales de crédito agrícola y ejidal & 12 & & & & $\mathrm{VI}$ & IV g & V & & \\
\hline Sociedades cooperativas de consumo & 12 & VIII & V & V & $\mathrm{x}$ & IV i & VII & VII & VII \\
\hline Sociedades cooperativas de productores & 12 & VIII & & & & IV h & & & \\
\hline Organismos que agrupen a las sociedades cooperativas & 11 & & & & & $\mathrm{IVi}$ & VIII & VIII & VIII \\
\hline $\begin{array}{l}\text { Sociedades mutualistas /Fondos de Aseguramiento Agro- } \\
\text { pecuario y Rural }\end{array}$ & 11 & & & & $\mathrm{x}$ & IV i & IX & IX & IX \\
\hline $\begin{array}{l}\text { Sociedades o asociaciones civiles que se dediquen a la } \\
\text { enseñanza }\end{array}$ & 2 & & IV & IV & VII & IV a & $\mathrm{X}$ & $\mathrm{x}$ & $X$ \\
\hline $\begin{array}{l}\text { Sociedades o asociaciones civiles dedicadas a la ciencia o } \\
\text { tecnología }\end{array}$ & 2 & IV & II & ॥ & III & IV $f$ & $\mathrm{XI}$ & $\mathrm{XI}$ & $\mathrm{XI}$ \\
\hline Sujetos que se dediquen a la edición de libros culturales & 2 & & & & VIII & $\mathrm{IV} \mathrm{b}$ & & & \\
\hline $\begin{array}{l}\text { Asociaciones o sociedades civiles dedicadas a la difusión } \\
\text { de música, artes plásticas, artes dramáticas, danza, litera- } \\
\text { tura }\end{array}$ & 12 & IV & & & & IV $f$ & & XII & XII \\
\hline Ejidatarios & 12 & & & & VI & IV c & & & \\
\hline $\begin{array}{l}\text { Las instituciones o sociedades civiles administradoras de } \\
\text { fondos o cajas de ahorro, y las sociedades cooperativas de } \\
\text { ahorro y préstamo. }\end{array}$ & 12 & & & & & & XII & XIII & XIII \\
\hline Asociaciones de padres de familia & 12 & & & & & & & XIV & XIV \\
\hline $\begin{array}{l}\text { Sociedades de gestión colectiva constituidas de acuerdo } \\
\text { con la Ley Federal del Derecho de Autor. }\end{array}$ & 12 & & & & & & & $X V$ & $X V$ \\
\hline $\begin{array}{l}\text { Asociaciones o sociedades civiles organizadas con fines } \\
\text { políticos, o asociaciones religiosas }\end{array}$ & $7 / 10$ & IV & $\|$ & II & III & IV $f$ & $\mathrm{XI}$ & $\mathrm{XVI}$ & $\mathrm{XVI}$ \\
\hline Asociaciones o sociedades civiles otorguen becas & 4 & & & & & & & $X V I I$ & $\mathrm{XVII}$ \\
\hline $\begin{array}{l}\text { Asociaciones civiles de colonos y administradoras de in- } \\
\text { muebles de propiedad en condominio }\end{array}$ & 6 & & & & & & & $\mathrm{XVIII}$ & $\mathrm{XVIII}$ \\
\hline
\end{tabular}

27 Instituto Mexicano de Contadores Públicos, A.C. Régimen Fiscal del Sector Primario (Agricultura, Ganadería, Pesca, Silvicultura). Ciudad de México, Instituto Mexicano de Contadores Públicos, A.C., 2011. 


\section{Esquemas tributarios de las entidades No lucrativas en México}

Volumen 12, Número 22 ene-jun 2020

Daniel Eduardo Paz Pérez

\begin{tabular}{|c|c|c|c|c|c|c|c|c|c|}
\hline Persona moral exenta o no contribuyente & CIOSFL & 1924 & 1925 & 1941 & 1953 & 1964 & 1980 & 2002 & 2013 \\
\hline $\begin{array}{l}\text { Las sociedades o asociaciones civiles que realicen investi- } \\
\text { gación o preservación de la flora o fauna silvestre }\end{array}$ & $2 / 5$ & & & & & & & XIX & XIX \\
\hline $\begin{array}{l}\text { Las asociaciones y sociedades civiles dedicadas a la re- } \\
\text { producción de especies en peligro de extinción }\end{array}$ & 5 & & & & & & & $X X$ & $X X$ \\
\hline $\begin{array}{l}\text { Las sociedades de inversión especializadas en fondos } \\
\text { para el retiro }\end{array}$ & 12 & & & & & & & *2 & XXI \\
\hline Los partidos y asociaciones políticas legales & 7 & IV & $\|$ & ॥ & III & III & ${ }^{* 1}$ & *3 & XXII \\
\hline $\begin{array}{l}\text { La Federación, las entidades federativas, los municipios y } \\
\text { las instituciones obligadas a entregar el remanente de ope- } \\
\text { ración. }\end{array}$ & 12 & VII & VI & VI & 1 & 1 & & *3 & XXIII \\
\hline $\begin{array}{l}\text { Los organismos descentralizados que no tributen conforme } \\
\text { al Título II de esta Ley }\end{array}$ & 12 & & VI & VI & I & 1 & & *3 & XXIV \\
\hline Propietarios de un solo automóvil de alquiler p/pasajeros & 12 & & & & IX & IV d & & & \\
\hline Explotación de películas nacionales & 12 & & & VII & & & & & \\
\hline $\begin{array}{l}\text { Sociedades o asociaciones civiles dedicadas a actividades } \\
\text { cívicas, derechos humanos, promoción de equidad, fo- } \\
\text { mento educativo, cultural, científico }\end{array}$ & $2 / 4 / 8$ & & & & & & & & $X X V$ \\
\hline $\begin{array}{l}\text { Asociaciones Deportivas reconocidas por la Comisión Na- } \\
\text { cional del Deporte }\end{array}$ & 12 & & $\|$ & $\|$ & III & IV f & $\mathrm{XI}$ & $\mathrm{XVI}$ & $X X V I$ \\
\hline $\begin{array}{ll}\text { *1- incluida en el texto del art. 73. } & \text { *2- incluida en e } \\
{ }^{*} \text { 3- incluida en el texto del art 102. } & \text { *4- excluidas en }\end{array}$ & $\begin{array}{l}\text { extc } \\
\text { is le }\end{array}$ & la & $\begin{array}{l}35 . \\
\text { erio }\end{array}$ & & & & & & \\
\hline
\end{tabular}

Fuente: Elaboración propia con base en las Leyes de ISR mexicanas del siglo XX en adelante.

\section{METODOLOGÍA}

El presente es un estudio descriptivo de tipo transversal; siendo del tipo documental, el trabajo incluyó una revisión y análisis históricos de la legislación fiscal mexicana vigente al segundo semestre de 2019, para la construcción del marco teórico de referencia; ya que el objetivo de la investigación es conocer el sistema tributario aplicable a las ENL, se utilizó el método interpretativo exegético o gramatical, que es el referido por el artículo 5 del CFF para el análisis en materia tributaria28 29 . A partir de los estudios del tema en la literatura reciente, surge la siguiente proposición teórica: "Existe más de un esquema tributario aplicable a las entidades no lucrativas y es diferente al resto de las organizaciones colectivas".

${ }^{28}$ Anchondo Paredes, V. E. Métodos de interpretación jurídica. Quid luris Núm. 16, 2012, pp. 33-58.

${ }^{29}$ Rafael Antúnez Álvarez. El Derecho Fiscal y su interpretación. Zapopan, Jalisco, Editorial Seo de Urgel, SA de CV., 2012. 


\section{RESULTADOS}

\section{El régimen tributario aplicable a las ENL}

La Ley del Impuesto Sobre la Renta vigente en 2019 contiene los siguientes regímenes para las personas morales, que son:

a) El Título II, que contiene el Régimen General de Ley donde tributan las empresas lucrativas, además de los siguientes grupos de contribuyentes: las instituciones de crédito, seguros y fianzas, almacenes generales de depósito, arrendadoras financieras y uniones de crédito, grupos de sociedades (antes holdings o controladoras), coordinados (dedicados al transporte) y actividades agrícolas, ganaderas, silvícolas y pesqueras.

b) El Título III, donde se ubica el Régimen de las Personas Morales con Fines No Lucrativos, diseñado exclusivamente para las entidades señaladas en el art. 95, cuyo listado se muestra en la Tabla 2.

Las ENL pueden acceder al Título III (b) siempre que reúnan todos los requisitos previstos en la Ley para cada sujeto, y algunas de ellas pueden convertirse en entidades receptoras de donativos deducibles de impuestos para quienes los otorguen cuando soliciten un registro especial para tal fin ante la autoridad tributaria, lo que las configura como Donatarias Autorizadas con algunos beneficios fiscales; por otra parte, el Régimen General de Ley (a) le es aplicable a las personas morales que no hayan optado por un régimen alterno, o bien que no reúnan los requisitos para tributar en el Título III; como ejemplo, una escuela constituida como Asociación Civil que no tenga Registro de Validez Oficial de Estudios (RVOE) otorgado por la autoridad educativa, deberá tributar en el Título II, en lugar de hacerlo en el Título III, ya que carece del requisito fundamental, esto lo recoge el criterio normativo 38/ISR/N de la Resolución Miscelánea Fiscal (RMF) para 2019.

En su artículo 79, la Ley de ISR vigente señala: "No son contribuyentes del impuesto sobre la renta, las siguientes personas morales:... ", con lo que se les reconoce a dichos sujetos el no ser causantes del impuesto, cuando las leyes anteriores señalaban que estaban exentos del pago del impuesto; esta es una modificación importante, para evitar la confusión que causa la prohibición del artículo 28 constitucional de la exención de impuestos, la cual cuando se otorgue debe ser abstracta, 


\section{Esquemas tributarios de las entidades No lucrativas en México}

\section{Volumen 12, Número 22 ene-jun 2020}

Daniel Eduardo Paz Pérez

general e impersonal y debe considerar situaciones objetivas que reflejen los intereses sociales y económicos en favor de ciertas categorías de sujetos 3031.

\section{Cálculo y declaración de Remanente Distribuible}

Como todas las organizaciones, las ENL perciben ingresos y realizan erogaciones para realizar el fin social; el artículo 80 de la Ley del ISR obliga a las personas morales de este Título a determinar los ingresos obtenidos, las erogaciones realizadas y el remanente distribuible, aún cuando no fuere entregado a los integrantes, pero aclara que sus integrantes solo deben declararlo cuando lo perciban en efectivo o especie (ver figura 1); el segundo párrafo del mismo artículo señala que para el cálculo de dichos conceptos, se utilizará lo dispuesto en los términos del Título ll si la mayoría de los socios fueren personas morales, o del Título IV si la mayoría de los socios fueren personas físicas; además, el octavo párrafo del artículo 86 obliga a los sujetos comprendidos en las fracciones $V$ a XIX y XXV del artículo 79 a presentar una declaración anual de ingresos y deducciones, aunque no se señala la obligación de calcular y enterar el impuesto ni la forma de determinarlo.

Figura 1.- Esquema tributario general de las entidades no lucrativas.

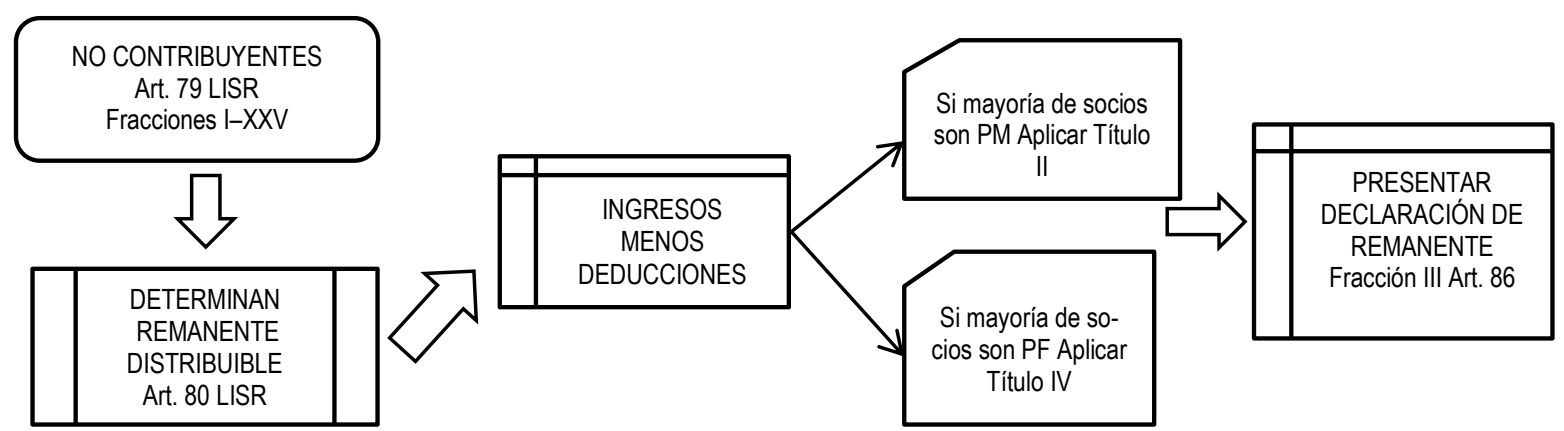

Fuente: Elaboración propia con base en la LISR 2019.

30 Francisco Ponce y Rodolfo Ponce. Derecho Fiscal Décima segunda edición. México: Editorial Limusa Noriega, 2012.

31 Rodríguez Mejía, G. Las Exenciones de Impuestos. Boletín Mexicano de Derecho Comparado, Número 94, 1999. Disponible en: <https://revistas.juridicas.unam.mx/index.php/derecho-comparado/article/view/3578/4303>. Fecha de acceso: 15 abr. 2020. 
En el caso de que el remanente calculado por la ENL fuera distribuido a sus integrantes personas físicas, tales contribuyentes en lo individual deberán presentar su declaración propia conforme al Tíitulo IV de la Ley de ISR y calcular y enterar el impuesto por la parte proporcional del remanente recibido; si el integrante fuera otra persona moral, deberá realizar el mismo procedimiento pero conforme al Título II de la misma Ley.

\section{Esquema tributario de las entidades no lucrativas en casos especiales}

Caso A. El penúltimo párrafo del artículo 79 señala que algunas personas morales de las mencionadas en los párrafos anteriores (ver figura 2) deberán determinar el remanente distribuible, aunque no lo hubiera efectivamente (remanente ficto) en los supuestos que señala dicho apartado: 1) cuando se omitan ingresos en los registros contables, 2) cuando no se contabilicen compras efectuadas o no se hayan realizado, 3) cuando se tengan erogaciones no deducibles por no cumplir los requisitos legales (excepto la falta del comprobante fiscal o no haberse pagado con cheque) y 4) los préstamos a socios o integrantes y sus familiares directos; dicho remanente deberá ser informado a la autoridad fiscal en la declaración que se presenta por el ejercicio en que ocurra el supuesto, en febrero del siguiente año; la ley señala que por dicho remanente la persona moral deberá calcular el impuesto aplicando la tasa máxima contenida en el artículo 152 del Título IV, que para el año 2019 es el 35 \%.

Figura 2.- Esquema tributario de las ENL del caso $A$.

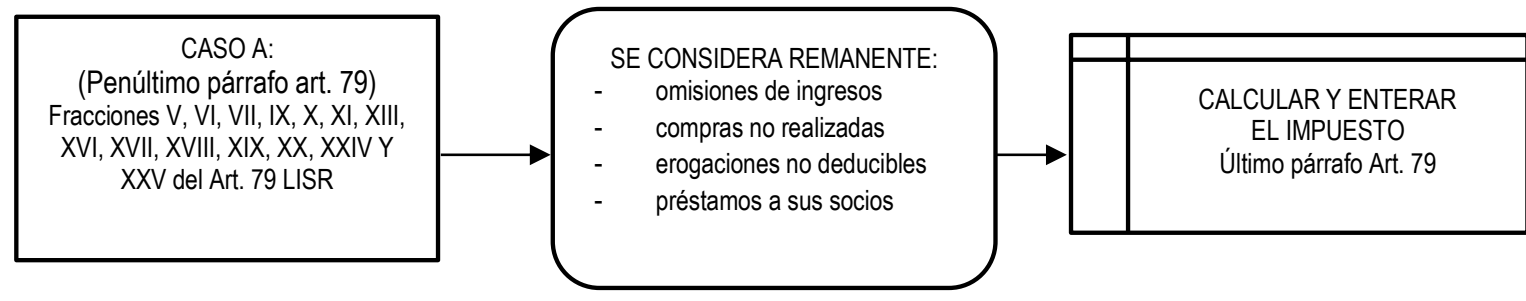

Fuente: Elaboración propia con base en la LISR 2019.

Caso B. De igual forma, las personas morales de este Título aún reconocidas como no causantes del impuesto, sí deberán calcularlo en el supuesto de que enajenen bienes distintos de su activo fijo 0 presten servicios a personas distintas de sus miembros o socios, para lo cual deberán calcular la utilidad de las actividades mencionadas en los términos del Título II o Régimen de Ley, y aplicar la tasa de ISR vigente, solo en el caso de que dichos ingresos excedan del $5 \%$ de los ingresos totales del ejercicio 


\section{Esquemas tributarios de las entidades No lucrativas en México}

\section{Volumen 12, Número 22 ene-jun 2020}

Daniel Eduardo Paz Pérez

anual, conforme al penúltimo párrafo del artículo 80 (ver figura 3); lo anterior no será aplicable en los siguientes casos:

- Tratándose de contribuyentes que presten servicios educativos con reconocimiento (escuelas con RVOE), a quienes les aplica el criterio normativo 39/ISR/N de la RMF para 2019.

- Tratándose de Asociaciones Religiosas, para quienes se emiten resoluciones generales 0 particulares para darles a conocer el régimen fiscal aplicable por cada ejercicio fiscal.

- Tratándose de las cooperativas de consumo, a quienes les aplica el criterio normativo 37/ISR/N de la RMF para 2019.

En tales casos el servicio que se presta no va dirigido a los socios o integrantes, como sería el caso de un colegio de profesionistas, sino a estudiantes y feligreses que no tienen la calidad de "personas distintas de sus miembros o socios"; caso distinto el de los cooperativistas, a quienes se les concede como un beneficio fiscal; por otro lado, el criterio no vinculativo 37/ISR/NV señala que las Asociaciones Deportivas que tributan en el Título III deberán pagar el impuesto cuando realicen actividades comerciales que rebasen el límite de ingresos señalado antes.

Figura 3.- Esquema tributario de las ENL del caso B.

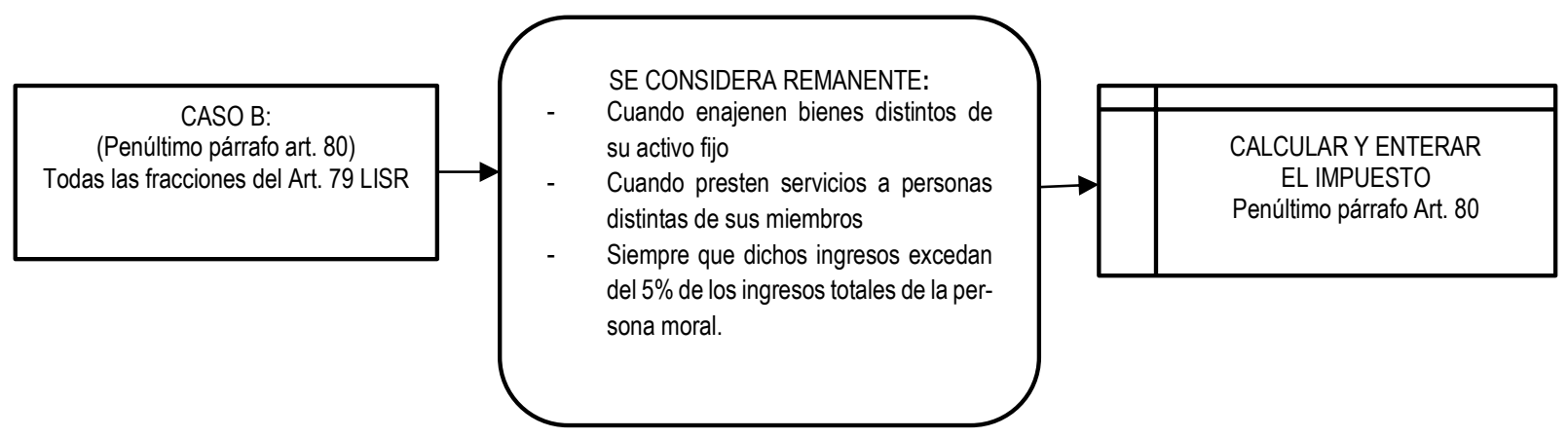

Fuente: Elaboración propia con base en la LISR 2019.

Caso C. También señala el artículo 81 de la Ley que en el caso de percibir ingresos por enajenación de bienes, intereses y obtención de premios, estos sujetos sí serán contribuyentes del Impuesto Sobre la Renta, excepto cuando quien perciba dichos ingresos sea una sociedad de inversión especializada en fondos para el retiro (Siefores) o una persona moral autorizada para recibir donativos 
deducibles de impuestos; estas últimas se configuran como Donatarias Autorizadas al cumplir los requisitos previstos en el artículo 82 de la LISR. Sin embargo, el obtener otra clase de ingresos no implica dejar de ser una persona moral no contribuyente, sino solamente le obliga a determinar y enterar el impuesto por las ganancias afectas a dicho acto conforme al Título II, quedando los demás ingresos con el tratamiento fiscal previsto en el Título III (ver figura 4).

El artículo 86 señala atinadamente que las entidades que no determinen remanente distribuible quedan relevadas de presentar la declaración anual y entregar constancias a sus integrantes; conforme al artículo 80, todas las entidades deben calcular el remanente, pero en ocasiones no existe un remanente distribuible; sería el caso de las entidades sin operaciones en el ejercicio o cuyo resultado no arroje un remanente.

Figura 4.- Esquema tributario de las ENL del caso C.

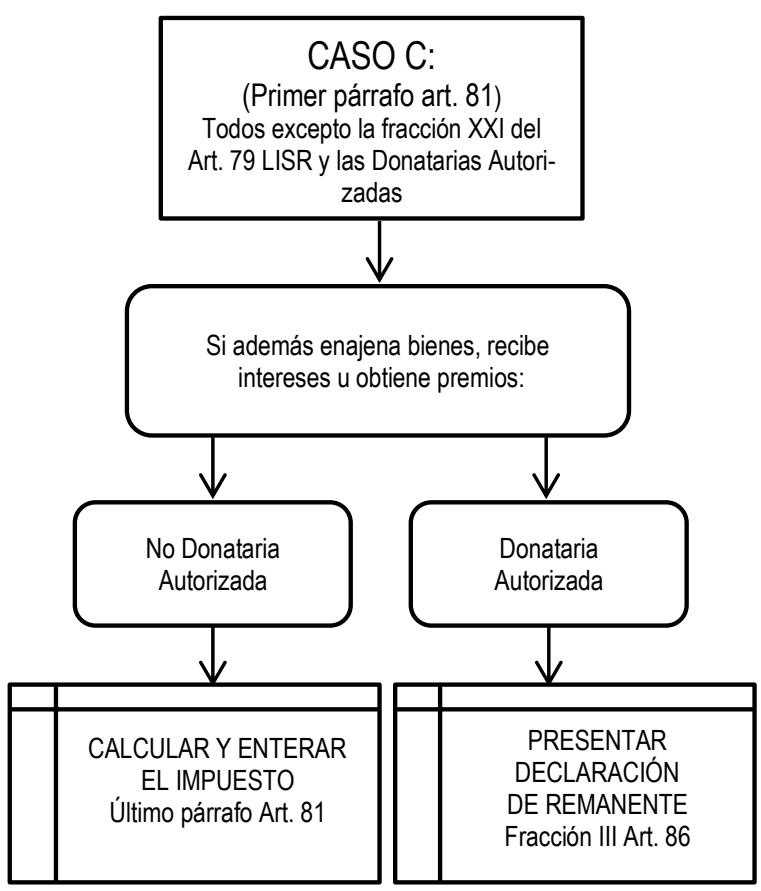

Fuente: Elaboración propia con base en la LISR 2019. 


\section{Esquemas tributarios de las entidades No lucrativas en México}

\section{Volumen 12, Número 22 ene-jun 2020 \\ Daniel Eduardo Paz Pérez \\ CONCLUSIONES}

Existen algunos beneficios para las organizaciones que se constituyen como entidades no lucrativas; el primer beneficio fiscal es ser considerada como una persona moral no contribuyente de impuestos en México; para su reconocimiento, la autoridad tributaria toma en cuenta las características del sujeto $y$, siendo conveniente que las ENL realizan actividades socialmente necesarias, les exime de la regla general de causación; otro beneficio es que en los casos en que se cause impuesto por caer en un supuesto jurídico particular, solo se causará el impuesto respecto de dicho acto y no por los demás ingresos que obtenga la persona moral; otros beneficios que pueden percibir algunas ENL son la eliminación parcial de obligaciones formales, como presentar declaraciones provisionales, llevar contabilidad, enviar contabilidad electrónica, expedir constancias, etc.

Se puede reconocer que el sistema tributario mexicano es benéfico con las ENL al considerar que no son causantes del Impuesto Sobre la Renta, excepto en los tres casos señalados previamente: 1) cuando realicen actos que les están prohibidos expresamente en Ley, 2) cuando presten servicios a no socios en más del $5 \%$ de sus ingresos (con algunas excepciones recogidas en los criterios normativos de la RMF o en resoluciones particulares otorgadas) y 3) cuando además de su objeto social perciban ingresos por intereses y premios; en otras situaciones existe solamente la obligación de calcular y declarar el remanente distribuible, y además se permite no declarar si no se ha obtenido un remanente de operación; lo anterior configura diversos esquemas tributarios para dichas organizaciones, que además son diferentes a los de las entidades lucrativas.

\section{DISCUSIÓN}

Las disposiciones fiscales establecidas para las entidades no lucrativas dan cuenta de los beneficios que éstas poseen para desarrollar sus finalidades en la sociedad mexicana, como actividades estratégicas para asegurar su éxito y supervivencia, de la misma forma en que son tratadas en otras legislaciones nacionales, donde suelen estar exentas del impuesto sobre ganancias (ISR), del impuesto sobre las ventas (IVA) y gozan de reducción o eliminación de otras obligaciones fiscales ${ }^{32}$.

32 ONU. Manual sobre las instituciones sin fines de lucro en el Sistema de Cuentas Nacionales. Nueva York, Departamento de Asuntos Económicos y Sociales, Naciones Unidas, 2007. 
El estudio reafirma la proposición teórica ofrecida: mientras la no causación del impuesto se otorga a priori a todas las entidades no lucrativas comprendidas en el listado del artículo 79 de la Ley de Renta, las excepciones a la misma establecidas para algunas de ellas en los artículos 80 al 89 del Título III les restringen o eliminan dicha facilidad; también, ciertas organizaciones realizan libremente su objeto social sin mayor regulación, mientras que otras deben solicitar autorización especial para no causar el impuesto, como las escuelas particulares y las entidades que reciben donativos, que deben pedir autorización para recibirlos 3334 35; de esta tesitura se colige que algunas entidades no lucrativas gozan de mayores beneficios en nuestro sistema tributario que otras de su mismo tipo.

Pese a su importancia, las entidades no lucrativas en México aún enfrentan los problema de la complejidad del entorno fiscal y legal, o su utilización indebida para evadir cargas fiscales al abusar de los donativos o tercerizar la nómina 363738 39; con todo, Butcher 40 y Vottero 41 consideran a estas entidades como brazos continuadores de la actividad social del Estado, a quienes hay que ver más allá desde la perspectiva recaudatoria, de las cuales se sugiere un estudio más a fondo para su mejor comprensión.

${ }^{33}$ Chávez-Chávez, J. L. La planeación fiscal a través de las asociaciones civiles. INCEPTUM, Vol. XIII, No. 24, 2018, pp. 322

${ }^{34}$ Cemefi. Centro Mexicano para la Filantropía AC. Recuperado el 4 de julio de 2018, de Entorno Regulatorio de las Organizaciones de la Sociedad Civil en México, 2015. Disponible en http://148.240.65.99/altaircif/Doctoelectronico/12665.pdf

${ }_{35}$ Rosiles-López et al. Legalidad de la Reforma Fiscal Para Sociedades y Asociaciones Civiles Dedicadas a la enseñanza, Efecto en Su Competitividad Operativa. Revista Global de Negocios Vol 4 Núm. 3, 2016, pp. 31-42.

${ }^{36}$ Carlos Chávez-Becker, Pablo González-Ulloa y Gustavo Adolfo Venegas-Maldonado. Retos, perspectivas y horizontes de las organizaciones de la sociedad civil en México. Los caminos hacia una reforma de la LFFAROSC. Ciudad de México, Instituto Belisario Domínguez del Senado, 2016.

${ }^{37}$ González Rodríguez, A. Efectos fiscales en las sociedades civiles. Contaduría Pública, 2011, pp. 2-9.

38 Ibarra-Baidón, C., \& Palos-Sosa, M. E. Reflexiones en torno al contexto organizacional y fiscal de los emprendimientos sociales en México. Diagnóstico FACIL Empresarial Año 9 - Núm. 17, 2017, pp.18-24.

${ }^{39}$ Rodrigo Villar, Jacqueline Butcher, Luciana Gandini, y Santiago Sordo. Fundaciones empresariales en México: un estudio exploratorio. Ciudad de México, Centro de Investigación y Estudios sobre Sociedad Civil, A.C., 2014.

40 Jacqueline Butcher. Tercer sector y desarrollo en México. En A. Girón, Del "vivir bien" al "buen vivir" entre la economía feminista, la filantropía y la migración: hacia la búsqueda de alternativas (págs. 91-112). Ciudad de México, UNAM, Instituto de Investigaciones Económicas, 2014.

${ }^{41}$ Nicolás Vottero. Tratamiento tributarios de las entidades sin fines de lucro. Córdoba, Argentina, Tesis de grado, Universidad Nacional de Córdoba, 2015. 


\section{Esquemas tributarios de las entidades No lucrativas en México}

\section{Volumen 12, Número 22 ene-jun 2020}

Daniel Eduardo Paz Pérez

\section{Referencias}

ABOITES, Luis. Excepciones y privilegios. Modernización tributaria y centralización en México, 1922-1972. México DF, El Colegio de México, Centro de Estudios Históricos, 2003.

ALTAMIRANO CÁRDENAS, J. Reyes. La Reforma al Sistema de Aseguramiento Agropecuario y la Participación de los Productores Organizados en la Operación del Seguro. Ciudad de México, Comisión Nacional de Seguros y Fianzas, 2001.

ANCHONDO PAREDES, Victor Emilio. Métodos de interpretación jurídica. Quid luris Núm. 16, 2012, pp. 33-58.

ANTÚNEZ ÁLVAREZ, Rafael. El Derecho Fiscal y su interpretación. Zapopan, Jalisco, Editorial Seo de Urgel, SA de CV. 2012

BELMARES SÁNCHEZ, Javier. Bitácora Fiscal Enciclopédica 2005 3a Edición. Ciudad de México, Sistemas de Información Contable y Administrativa Computarizada, S.A. de C.V., 2005.

BUTCHER, Jacqueline. Tercer sector y desarrollo en México. En A. Girón, Del "vivir bien" al "buen vivir" entre la economía feminista, la filantropía y la migración: hacia la búsqueda de alternativas (págs. 91-112). Ciudad de México, UNAM, Instituto de Investigaciones Económicas, 2014.

BUTCHER, Jacqueline y VERDUZCO, Gustavo. Acción voluntaria y voluntariado en México. Ciudad de México, Fundación Telefónica México, S.A. de C.V; Ediciones Culturales Paidós, S.A. de C.V., 2016.

CALVO NICOLAU, Emiliano.Tratado del Impuesto sobre la Renta. México DF, Editorial Themis S.A., 2013.

CCPM. Entidades con Propósitos No Lucrativos. Comisión de Desarrollo del Colegio de Contadores Públicos de México, Boletín de Investigación No. 6, , 2013, pp.1-48.

CEMEFI. Centro Mexicano para la Filantropía AC. Recuperado el 4 de julio de 2018, de Entorno Regulatorio de las Organizaciones de la Sociedad Civil en México, 2015. Disponible en: http://148.240.65.99/altaircif/Doctoelectronico/12665.pdf

CENTRO INTERAMERICANO DE ADMINISTRACIONES TRIBUTARIAS. Los sistemas tributarios de América Latina. Breve repaso de la legislación. Serie Comparativa No. 1 , 2016, pp. 288-316.

CHÁVEZ-BECKER, Carlos, GONZÁLEZ-ULLOA, Pablo y VENEGAS-MALDONADO, Gustavo Adolfo. Retos, perspectivas y horizontes de las organizaciones de la sociedad civil en México. Los caminos hacia una reforma de la LFFAROSC. Ciudad de México, Instituto Belisario Domínguez del Senado, 2016.

CHÁVEZ-CHÁVEZ, José Luis. La planeación fiscal a través de las asociaciones civiles. INCEPTUM, Vol. XIII, No. 24, 2018, pp. 3-22.

ESCOBAR OHMSTEDE, Antonio. Desastres agrícolas en México. Catálogo histórico II. Siglo XIX (1822-1900). México, Fondo de Cultura Económica CIESAS, 2004.

FERNÁNDEZ, Leandro. Memoria de la Secretaría de Hacienda y Crédito Público correspondiente al septuagésimo primer año económico. Ciudad de México, Tipografía de la Oficina Impresora de Estampillas, Palacion Nacional, 1896.

FERNÁNDEZ-RUIZ, Jorge. Régimen Jurídico Municipal, Delegacional y Metropolitano. Ciudad de México, Instituto Nacional de Administración Pública, A.C., 2017.

\section{6}


GARDUÑO MARTÍNEZ, Alberto. Asociaciones Religiosas: ¿Entidades No Contribuyentes del Impuesto Sobre la Renta? Boletín Fiscal IEE, 2015, pp. 33-37.

GOBIERNO DEL ESTADO DE MÉXICO. Glosario de términos. Toluca, Gobierno del Estado de México, 2013.

GONZÁLEZ CASTILLO, Vinicio. Mejores prácticas administrativas para organizaciones no lucrativas. Revista Contaduría Pública Num. 428, 2008, pp. 8-10.

GONZÁLEZ RODRÍGUEZ, Antonio. Efectos fiscales en las sociedades civiles. Revista Contaduría Pública, 2011, pp. 2-9.

IBARRA-BAIDÓN, Claudia y PALOS-SOSA, Martha Elba. Reflexiones en torno al contexto organizacional y fiscal de los emprendimientos sociales en México. Diagnóstico FACIL Empresarial Año 9 - Núm. 17, 2017, pp. 18-24.

INEGI. Cuenta Satélite de las Instituciones sin Fines de Lucro de México, 2018. Ciudad de México, Instituto Nacional de Estadística y Geografía, 2018.

INEGI. Clasificación Internacional de Organizaciones Sin Fines de Lucro (CIOSFL) 2019. Ciudad de México, Instituto Nacional de Estadística y Geografía, 2019.

INSTITUTO MEXICANO DE CINEMATOGRAFÍA. Anuario estadístico de cine mexicano 2018. Ciudad de México, Instituto Mexicano de Cinematografía, 2019.

INSTITUTO MEXICANO DE CONTADORES PÚBLICOS, A.C. Régimen Fiscal del Sector Primario (Agricultura, Ganadería, Pesca, Silvicultura). Ciudad de México, Instituto Mexicano de Contadores Públicos, A.C., 2011.

IZQUIERDO, Martha E. Cooperativas de producción en México y reformas fiscales. Boletín de la Asociación Internacional de Derecho Cooperativo, 2016, pp. 103-126.

LEE GALINDO, Jorge. Ley de Asociaciones Religiosas y Culto Público Comentada. Ciudad de México, Editorial SISTA S.A. de C.V., 2009.

LÓPEZ CRUZ, Fernando. Dictamen Fiscal. México DF, Instituto Mexicano de Contadores Públicos, A.C., 2012.

ONU. Manual sobre las instituciones sin fines de lucro en el Sistema de Cuentas Nacionales. Nueva York, Departamento de Asuntos Económicos y Sociales de las Naciones Unidas, 2007.

PÉREZ-CERVANTES, Felipe, BIESE-DECKER, William Allan, CORTÉS-MORENO, Luis Antonio, GARCÍA-BOJORGES, Elsa Beatriz Y GRAS-GAS, Juan Mauricio. Normas de Información Financiera. Ciudad de México, Instituto Mexicano de Contadores Públicos, 2017.

PONCE, Francisco y PONCE, Rodolfo. Derecho Fiscal Décima segunda edición. México, Editorial Limusa Noriega, 2012.

REYES OSORIO, Sergio y REYES RIVES, Emiliano. La historia del crédito agrícola en México. Ciudad de México, Centro de Estudios para el Desarrollo Rural Sustentable y la Soberanía Alimentaria (CEDRSSA), 2018.

RODRÍGUEZ MEJÍA, Gregorio. Las Exenciones de Impuestos. Boletín Mexicano de Derecho Comparado, Número 94, 1999. Disponible en: <https://revistas.juridicas.unam.mx/index.php/derecho-comparado/article/view/3578/4303>. Fecha de acceso: 15 abr. 2020.

ROSILES-LÓPEZ, Leonel, MACÍAS-TERÁN, Cruz Elda, PÉREZ-ALCALÁ, Santiago, LEÓN-PRIETO, Julio César y GONZÁLEZ-NÚÑNEZ, Raúl. Legalidad de la Reforma Fiscal Para Sociedades y Asociaciones Civiles Dedicadas a la enseñanza, Efecto en Su Competitividad Operativa. Revista Global de Negocios Vol 4 Núm. 3, 2016, pp. 31-42. 


\section{Esquemas tributarios de las entidades No lucrativas en México}

\section{Volumen 12, Número 22 ene-jun 2020 \\ Daniel Eduardo Paz Pérez}

SECRETARÍA DE GOBERNACIÓN. Recopilación de Leyes y Decretos expedidos por los poderes Legislativo y Ejecutivo de la Unión de mayo a diciembre de 1917. México DF, Imprenta de la Secretaría de Gobernación, 1917.

SUÁREZ-NORIEGA, José Manuel. En busca de la liberta auto-organizada: emprendimiento juvenil. En Centro Mexicano de Filantropía, Memorias del XV Congreso de Investigación sobre el Tercer Sector (págs. 806-827). México DF, Cemefi, 2015.

VILLAR, Rodrigo, BUTCHER, Jacqueline, GANDINI, Luciana y SORDO, Santiago. Fundaciones empresariales en México: un estudio exploratorio. Ciudad de México, Centro de Investigación y Estudios sobre Sociedad Civil, A.C., 2014.

VOTTERO, Nicolás. Tratamiento tributarios de las entidades sin fines de lucro. Córdoba, Argentina, Tesis de grado, Universidad Nacional de Córdoba, 2015.

Recibido 5 de Junio de 2020

Aceptado 28 de Junio de 2020 